\title{
Birth Anthropometry Characteristics of Hypospadias Patients in Palembang, Indonesia
}

\author{
Savero Evan Abisha ${ }^{1}, Z_{\text {Ziske Maritska }}^{2, *}$ Triwani $^{2}$ \\ ${ }^{1}$ Faculty of Medicine, Universitas Sriwijaya \\ ${ }^{2}$ Department of Biology Medicine, Faculty of Medicine, Universitas Sriwijaya \\ \#Correspondence: ziske_kamil@yahoo.com \\ Received : June 20th 2019 \\ Accepted :August $20^{\text {th }} 2019$
}

\begin{abstract}
Background

Hypospadias is one of the most common urogenital anomaly in males. The etiology is poorly understood, but is believed to be multifactorial where Intra Uterine Growth Restriction (IUGR) is one of the suspected risk factors, leading to low birth weight and low birth length in affected patients.

Objective

This study aims to identify the birth anthropometry characteristics of hypospadias patients who visited RSUP. Dr. Mohammad Hoesin Palembang.

Materials and Methods

This was an observational descriptive study with cross sectional design. This study included hypospadias patients with detailed birth characteristics in RSUP Dr. Mohammad Hoesin Palembang during the period of 2012-2015.

Results

Out of 106 hypospadias patients, only $19(17.92 \%)$ of them presented with detailed birth characteristics. There were $12(63,2 \%)$ patients with low birth weight and $7(36,8 \%)$ patients with normal birth weight. There were $10(52,6 \%)$ patients with low birth length and $9(47,4 \%)$ patients with normal birth length. The mean birth weight is 2442 grams and the mean birth length is 46,9 centimeters.

Conclusion

The majority of hypospadias patients in this study showed a low birth weight and low birth length, signalling an accordance to the existing theory.
\end{abstract}

Keywords: Hypospadias, birth anthropometry, characteristics

\section{Introduction}

Hypospadias is an anterior urethral developmental disorder in which the urethral orifice lies ectopically on the ventral portion of the proximal penis to the glans penis. The urethral orifice may also lie in the scrotum or perineum, and the penis will progressively shorten and form a curvature called chordae ${ }^{1}$.

Hypospadias is one of the most common urogenital abnormalities in boys, with an incidence rate in the world of about 1:125 to 1:300 male births ${ }^{1}$. However, data on the incidence of hypospadias 


\section{ISSN 25980580}

in Indonesia is still limited. Based on data from several general hospitals in Balikpapan, Bali, and Manado, reported rates of hypospadias range from 17 to 53 patients over a three-year period in each of the hospitals.

Hypospadias condition will certainly cause various problems for the patients. Various problems that can occur includes reproductive, psychological, and social functions problems. Psychological and social impacts are not only felt by the patient itself, but can also affect the patient's parents. In some cases the hypospadias may appear similar to female genitals as the penis is attracted to the chordae and the scrotum is split, thus causing psychological stress for the patient's parents because of the uncertainty of the sex of the baby. Only few parents are aware of the consequences that can arise in patients with hypospadias. Some consider hypospadias as an insignificant disorder because of its hidden location and not visible from the outside, thus causing many patients with delayed handling of hypospadias, i.e. patients coming for therapy when they are already adults. In addition to ignorance, economic factors can also be one cause of not doing correction in hypospadias.

The etiology of hypospadias is poorly understood. It is believed to be multifactorial, with various associated risk factors. In addition to genetic factors, environmental factors have a large role in their influence on the incidence of hypospadias, especially those associated with maternal risk factors. Historical use of drugs and exposure to certain chemicals and cigarette smoking during pregnancy is known to be found in many patients with hypospadias ${ }^{2}$. Maternal age, history of hypertension, preeclampsia, and low birth weight and placental insufficiency are also known to be the triggers of hypospadias. Hormones used in contraceptive drugs may also increase the risk of hypospadias ${ }^{3}$.

In addition, another factor suspected to affect the incidence of hypospadias is Intrauterine Growth Restriction (IUGR). There are two basic phases that occur in the development of the male phenotype. The first stage is the development of the testes, which is usually determined by the presence of Y chromosomes, especially the SRY gene. The second stage involves the androgen effect through production by the testes based on the required response. Disability at any of these stages can cause abnormal sexual differentiation. External genitalia can not be distinguished until about the 8th week of pregnancy, when the differentiation of the male external genitalia begins. During this period, human chorionic gonadotropin (HCG) induces masculinization by stimulating testosterone and dihydrotestosterone (DHT) production by fetal testicular interstitial cells. The union of the urethral fold is usually completed around the 16th week of pregnancy. Thus, various environmental and 


\section{ISSN 25980580}

hormonal disturbances, including the cause of IUGR, occurring before or during this period may cause hypospadias.

Based on this theory, hypospadias patients have birth weight, body length, and head circumference that is lower than normal. Furthermore, it is expected that the fetus who have IUGR can be screened for early detection of hypospadias. Therefore, in this research will be collecting anthropometry data to get the characteristics of body length, head circumference, and birth weight of hypospadias patients in Palembang.

\section{Materials and Methods}

This study uses descriptive observational method with cross sectional design to know the anthropometry characteristics of hypospadias patient born in Palembang in 2012-2015. The study was conducted in November-December 2016 in the Medical Record Division of Dr. Mohammad Hoesin Palembang.

The subjects of the study were medical record data of hypospadias patients in RSUP Dr. Mohammad Hoesin Palembang in 2012-2015 taken using the total sampling method. The variables studied were birth weight and body length. Data were processed univariat and presented in frequency distribution table.

However, of all 106 recorded hypospadias patients during that period, only 19 hypospadias patients presented with detailed data of birth weight and birth length.

\section{Results}

There are 106 hypospadias patients in RSUP Dr. Mohammad Hoesin Palembang in 2012-2015. All hypospadias patients taken as sample of this study were aterm. Maternal age distribution when giving birth in this study was $14(73,7 \%) \leq 35$ years old mother and $5(26,3 \%)>35$ years old mother. Based on the number of parities, there were 12 (63.2\%) mothers with primiparas and $7(36.8 \%)$ mothers with multiparas (Table 1). Of the 19 patients, 12 (63.2\%) patients were born with a weight below the normal limit and 7 (36.8\%) of patients were born with a normal weight (Table 2). The mean birth weight of hypospadias patients in this study was 2442 grams. The number of patients born with a body length below the normal limit was $10(52.6 \%)$ patients and $9(47.4 \%)$ patients were born with body length within normal limit (Table 3). The mean birth weight of hypospadias patients in this study was $46,9 \mathrm{~cm}$. There were 7 (36.8\%) patients born with birthweight 
and body length below the normal limit, 5 (26.3\%) patients with low birth weight alone, 3 (15.8\%) patients with low birth length alone, and $4(21.1 \%)$ patients with normal birth weight and birth length (Table 4).

Table 1. Maternal distribution by age and parities $(\mathrm{N}=19)$

\begin{tabular}{lll}
\hline Characteristics & n & \% \\
\hline Age & & \\
$\leq 35$ years old & 14 & 73,7 \\
>35 years old & 5 & 26,3 \\
Parities & & \\
Primipara & 12 & 63,2 \\
Multipara & 7 & 36,8 \\
\hline
\end{tabular}

Table 2. Hypospadias patients distribution by birth weight $(\mathrm{N}=19)$

\begin{tabular}{lll}
\hline Birth weught & n & \% \\
\hline Under normal limits & 12 & 63,2 \\
Within normal limits & 7 & 36,8 \\
Above normal limits & 0 & 0 \\
\hline Total & $\mathbf{1 9}$ & $\mathbf{1 0 0}$ \\
\hline
\end{tabular}

Table 3. Hypospadias patients distribution by birth length $(\mathrm{N}=19)$

\begin{tabular}{lll}
\hline Birth length & $\mathbf{n}$ & $\mathbf{\%}$ \\
\hline Under normal limits & 10 & 52,6 \\
Within normal limits & 9 & 47,4 \\
Above normal limits & 0 & 0 \\
\hline Total & $\mathbf{1 9}$ & $\mathbf{1 0 0}$ \\
\hline
\end{tabular}

Table 4. Hypospadias patients distribution by anthropometry interpretation $(\mathrm{N}=19)$

\begin{tabular}{lll}
\hline Anthropometry Interpretation & n & \% \\
\hline Both low birth weight and low & 7 & 36,8 \\
birth length & & \\
Low birth weight & 5 & 26,3 \\
Low birth length & 3 & 15,8 \\
$\begin{array}{l}\text { Normal birth weight and birth } \\
\text { length }\end{array}$ & 4 & 21,1 \\
\hline Total & $\mathbf{1 9}$ & $\mathbf{1 0 0}$ \\
\hline
\end{tabular}

\section{Discussion}

This study found 12 (63.2\%) patients born with weight under normal limits and 7 (36.8\%) patients born with weight within normal limits. Patients born with body length below the normal limit were $10(52.6 \%)$ patients and those born with normal weight were $9(47.4 \%)$ patients. There were 7 (36.8\%) patients born with both anthropometric aspects below the normal limit, 5 (26.3\%) patients with low birth weight only, $3(15.8 \%)$ patients with low birth length only, and $4(21.1 \%)$ patients with normal birth weight and birth length. The mean birth weight of hypospadias patients in this study was 2442 grams and the mean birth weight was $46,9 \mathrm{~cm}$. 


\section{ISSN 25980580}

The results of this study are in accordance with research conducted by Chen Min-Jye in 2014 and Hussain in 2002. Research conducted by Chen Min-Jye found that hypospadias patients tend to have lower birth weight than those who are not hypospadias, but birth length and head circumference of hypospadias were not studied. Chen Min-Jye's research used the same criteria as this study to determine the classification of birth weight, i.e. low birth weight were less than 2500 grams.

Meanwhile, Hussain's study found a significant association between hypospadias and IUGR that can be seen from body size below normal limits on all three aspects of anthropometry (body weight, body length, and head circumference). The combination of these three aspects of anthropometry suggests a growth restriction during early pregnancy. Hussain's study used WHO criteria to determine anthropometric classification, in which patient was considered to be below normal limits when less than the $10^{\text {th }}$ percentile. Various other studies have also found an association between hypospadias and birth weight, although the difference is not always statistically significant ${ }^{4}$.

The conformity of these results shows the relationship between hypospadias and birth anthropometry characteristics. Hypospadias patients tend to have lower than normal anthropometry characteristics. One of the things that is suspected to be the main cause of hypospadias and IUGR is placental insufficiency ${ }^{5}$. There are two basic phases that occur in the development of the male phenotype. The first phase is the development of the testes determined by the presence of $\mathrm{Y}$ chromosome and the second phase involves androgens. Disorders in either phase may result in abnormal sexual differentiation ${ }^{6}$.

External genitalia can not be distinguished until approximately the $8^{\text {th }}$ week of pregnancy, when the differentiation of the male external genitalia begins. During this period, human chorionic gonadotropin (HCG) induces virilization by stimulating testosterone production and dihydrotestosterone (DHT) by fetal testicular interstitial cells. The union of the urethral fold is usually completed around the $16^{\text {th }}$ week of pregnancy. If placental insufficiency occurs at weeks 8 to 16 it will lead to a decrease in the distribution of HCG to the fetus, so that testosterone and DHT levels become inadequate to induce virilization. Lack of HCG distribution and other nutritional intake to the fetus result in hypospadias and IUGR. However, it should be noted that both conditions arise simultaneously only when placental insufficiency occurs during the union fold period of the urethra (weeks 8 to 16). If placental insufficiency occurs after that period, it may only cause IUGR without hypospadias because the union of the urethral fold is completed by the $16^{\text {th }}$ week. The duration of 


\section{ISSN 25980580}

placental insufficiency is also very important because if it happens only briefly there may not be a significant difference ${ }^{5}$.

In addition, this study obtained some samples that experienced either low birth weight or low birth length only, where low birth weight was more common than low birth length. This suggests that hypospadias may have a more significant association with birth weight compared to birth length, whereas reference suggests that all three aspects of birth anthropometry in hypospadias patients decreased proportionally ${ }^{7}$. Differences in our results may be due to other factors not investigated in this study, such as genetic factors, nutritional intake during pregnancy, or the consumption of certain drugs.

\section{Conclusion}

Majority of hypospadias patients in this study had birth weight and birth weight below normal limits. There were 12 (63.2\%) patients with low birth weight (mean birth weight 2442 grams) and there were $10(52.6 \%)$ patients with low birth weight (mean birth length $46,9 \mathrm{~cm}$ ). Of the 12 patients, $7(36.8 \%)$ patients were born with both low birth weight and low birth length, 5 (26.3\%) patients with low birth weight only, 3 (15.8\%) patients with low birth length only, and 4 (21.1\%) patients with both normal birth weight and normal birth length.

\section{References}

1. Baskin, L.S. dan Ebbers M.B. 2006. Hypospadias: anatomy, etiology, and technique. Journal of Pediatric Surgery. 2006: 41, 463-472.

2. Maritska, Ziske, Mahayu Dewi Ariani, Achmad Zulfa Juniarto, Sultana M.H. Faradz, dan Ardy Santosa. 2015. Profile of Hypospadias Casesin Central Java, Indonesia. Journal of Biomedicine and Translational Research 01.2015: 16-21.

3. Van Rooij, Iris A., Loes F.M. van der Zanden, Brouwers M.M., Knoers N.V., Feitz W.F., dan Roeleveld N. 2013. Risk Factors for Different Phenotypes of Hypospadias: Results from a Dutch Case-control Study. BJU International. 2013: 112, 121-128.

4. Hsieh, MH, Alonzo DG, Gonzales ET, Jones EA, Cisek LJ, Roth DR. 2011. Ex-premature infant boys with hypospadias are similar in size to age-matched, ex-premature infant boys without hypospadias. J Pediatr Urol. 2011 Oct; 7(5):543-7.

5. Chen, Min-Jye, Charles G. Macias, Sheila K. Gunn, Jennifer E. Dietrich, David R. Roth, Bruce J. Schlomer, dkk. 2014. Intrauterine Growth Restriction and Hypospadias: is There a Connection? International Journal of Pediatric Endocrinology. 2014:2014:20.

6. Kalfa, Nicolas, Sultan C, Baskin LS. 2010. Hypospadias: etiology and current research. Urol Clin North Am. 2010 May; 37(2):159-66. 
7. Hussain, N., Chaghtai A., Herndon C.D., Herson V.C., Rosenkrantz T.S., McKenna P.H. 2002. Hypospadias and Early Gestation Growth Restriction in Infants. Pediatrics. 2002 Mar;109(3):473-8. 